\title{
Allergic diseases of the skin and drug allergies - 2004: Clinical and immunologic characteristics of allergen-specific immunotherapy in children with atopic dermatitis
}

\author{
Tatiana Slavyanskaya ${ }^{1 *}$, Vladislava Derkach² \\ From 2nd WAO International Scientific Conference (WISC 2012) \\ Hyderabad, India. 6-9 December 2012
}

\section{Background}

The aim was to determine the dynamic of clinical symptoms and saliva concentrations (SC) of IL-4, IL-13, IFN $\gamma$ in children $(\mathrm{Ch})$ with atopic dermatitis (AD) in the setting of background therapy (BT) and accelerated parenteral allergen-specific immunotherapy (APAI) with house dust mite allergens (HDMA).

\section{Methods}

The study included a total of $33 \mathrm{Ch}$ with non-acute AD. The mean age at enrollment was 7.2 \pm 2.1 . The APAI has been provided for 36 months $(\mathrm{M})$ according to accelerated regimen by parenteral introduction of HDMA (2 times/ daythrough 6 h.), along with BT. SC of IL-4, IL-13, IFN $\gamma$ were measured using ELISA at 1, 3, 6, 12 and 36M after treatment initiation.

\section{Results}

The efficacy after 12M of APAI was 78.7-84.8\% depending on disease severity. The "excellent" result after APAI course was achieved in $21.2 \% \mathrm{Ch}$ with $\mathrm{AD}$, "good" in $57.6 \% \mathrm{Ch}$, "satisfactory" in $9.1 \% \mathrm{Ch}$, and there was no therapeutic effect in $12.1 \% \mathrm{Ch}$. There was reduction in the number, duration and severity of $\mathrm{AD}$ exacerbations observed in $2 / 3 \mathrm{Ch}$, which allowed the subsequent reduction of BT. As early as at $6 \mathrm{M}$ there was a 1.5 times decrease of hospitalization number $(\mathrm{p}<0.05)$ as compared to the pre-treatment year. After the 1st M of APAI in Ch with AD there was no significant decrease of SC of IL-4, IL-13 and no increase of saliva IFN $\gamma$ level either $(\mathrm{p}<0.05)$.
There was no normalization of SC IL-4 and IL-13 during first 6 months in Ch with severe AD as well, though their levels decreased at an average of more than 1.5 times. $12 \mathrm{M}$ of APAI provided duplication of local SC of IFN $\gamma$. This saliva IFN $\gamma$ increase in $\mathrm{Ch}$ with AD on the background of APAI was accompanied by decrease of specific IgE againstHDMA $(r=-0.73)$. The pre-APAI immune disorder formula was IL-43+IL-132+IFN $\gamma 3-$ IgE3+. After termination of treatment course withHDMA it has changed for IL-42+IL-132+IFN $\gamma 1-I g E 2+$.

\section{Conclusions}

The results showed that pathogenetic therapy contributes to reduction of SC and inhibits immune inflammation by down regulating the pro-inflammatory cytokine IL-4 and IL-13 production and activating IFN $\gamma$ synthesis. Thus the accelerated parenteral APAI is effective in $\mathrm{Ch}$ with $\mathrm{AD}$.

\section{Author details}

'Medical Faculty, Postgraduate Course, University of Russia, Moscow, Russia. 2Vladivostok State Medical University, Vladivostok, Russia.

Published: 23 April 2013

\section{doi:10.1186/1939-4551-6-S1-P94}

Cite this article as: Slavyanskaya and Derkach: Allergic diseases of the skin and drug allergies - 2004: Clinical and immunologic characteristics of allergen-specific immunotherapy in children with atopic dermatitis. World Allergy Organization Journal 2013 6(Suppl 1):P94. 